\title{
Overview of Quality of Life Research in Older People with Visual Impairment
}

\author{
Chong-Wen Wang1,2*, Cecilia L. W. Chan ${ }^{1,3}$, Iris Chi ${ }^{4,5}$ \\ ${ }^{1}$ Centre on Behavioral Health, The University of Hong Kong, Hong Kong, China \\ ${ }^{2}$ Department of Ophthalmology, Liyuan Hospital \& Hubei Geriatric Hospital, Tongji Medical College, Huazhong \\ University of Science and Technology, Wuhan, China \\ ${ }^{3}$ Department of Social Work \& Social Administration, The University of Hong Kong, Hong Kong, China \\ ${ }^{4}$ Sau Po Centre on Aging, The University of Hong Kong, Hong Kong, China \\ ${ }^{5}$ School of Social Work, University of Southern California, Los Angeles, USA \\ Email: *wangcw@hku.hk
}

Received 15 February 2014; revised 6 April 2014; accepted 22 April 2014

Copyright (C) 2014 by authors and Scientific Research Publishing Inc.

This work is licensed under the Creative Commons Attribution International License (CC BY). http://creativecommons.org/licenses/by/4.0/

(c) (i) Open Access

\begin{abstract}
During the past two decades, a number of studies have investigated the health-related quality of life (HRQOL) of older people with visual impairment, but the information is fragmented concerning health care providers in the field of gerontology. In this review, findings of HRQOL studies in older adults with different types of age-related ocular disorders or conditions are summarized. Apart from medical treatment and vision rehabilitation, factors that may influence the HRQOL of visually impaired older adults are also examined, including age, gender, socioeconomic status, mobility, comorbidity, family support, social support, use of eye care services, and psychological and spiritual factors. Finally, existing problems are discussed and recommendations for future research are provided. Given the high prevalence of visual impairment among older adults and their unmet needs for eye care and vision rehabilitation, multidisciplinary interventions that may enhance visually impaired older people's HRQOL are warranted.
\end{abstract}

\section{Keywords}

Older Adults, Quality of Life, Review, Vision Loss, Visual Impairment

\section{Introduction}

Populations are rapidly aging across the world. Visual impairment is a common and debilitating health problem

\footnotetext{
${ }^{*}$ Corresponding author.
} 
among older adults. According to the World Health Organization, there are an estimated 161 million visually impaired people (defined as having visual acuity lower than 6/18) around the world [1]. It is projected that the number of visual impairment cases will roughly be doubled worldwide by the year 2020 [2]. More than two thirds of all severely visually impaired people are 65 years old and above [3]. It is suggested that vision impairment affects about $10 \%$ of people aged $65-75$, and about $20 \%$ of those aged 75 or older [4]. A study revealed that the prevalence of visual impairment $(<6 / 18)$ in at least one eye was $41.3 \%$ among persons aged 60 and above and $73.1 \%$ in those 80 years of age or older [5]. The major causes of age-related visual impairment include cataract, macular degeneration, glaucoma, and diabetic retinopathy, but their distribution varies slightly across different countries [6]. As visual function is the most important sensory function of the human body, visual impairment is often detrimental to affected individuals' daily life and leads to functional disabilities and other health problems. Consequently, their quality of life (QOL) may significantly deteriorate.

During the past two decades, an increasing number of studies have investigated the impact of visual impairment on the QOL of older people. Although some review articles regarding the association of QOL with ocular disorders emerged in the literature [7]-[13], these reviews were generally performed from the perspective of specialists in the fields of ophthalmology and optometry, and mainly focused on particular disorders. The information is fragmented concerning health care providers or professionals in the field of gerontology. To date, there is still a lack of reviews on the QOL of older people with a wide range of age-related ocular disorders from a perspective of gerontology or population health. To fill this knowledge gap, this paper provides an overview of the progress of QOL research among visually impaired older adults, which will contribute to a better understanding of older adults' QOL and build stronger links between researchers in the fields of eye care and gerontology.

\section{Concept of Visual Impairment}

Vision function has multiple dimensions including central vision (how far away and how clearly an individual can see), peripheral vision or visual field (the scope of an individual sight), color vision, stereo vision, and contrast sensitivity [14]. Visual impairment refers to any loss or abnormality of visual functions [15]. Usually, vision loss is synonymous with visual impairment. In the fields of ophthalmology and optometry, moderate visual impairment is often defined as "low vision" [16]. The term "blindness", including legal blindness and total blindness, generally refers to severe visual impairment [16].

\subsection{Measurement of Visual Impairment}

Practically, visual impairment is most often measured objectively with vision tests of loss of central visual acuity (distance vision, near vision) and sometimes of loss or abnormality of visual field, color vision, or contrast sensitivity [14]. Given that central vision is most important for everyday function, it is generally used as the standard for comparison. Visual acuity is often scored as a set of two numbers, such as 20/40, which indicates that the patient's eye can only read from 20 feet letters that are large enough for a normal eye to read from 40 feet [14]. Usually, 20/20 or 6/6 vision is defined as normal. Practically, different criteria are used to define visual impairment in different countries (Table 1), which may make it difficult to precisely compare statistics across different studies. Objective measurement of visual impairment is generally used in medical settings.

Visual impairment can also be subjectively measured from the patient's perspective, since persons with cen-

Table 1. Definitions and criteria of visual impairment.

\begin{tabular}{|c|c|c|}
\hline Sources & Definitions & Criteria \\
\hline World Health Organization [15] & $\begin{array}{l}\text { Inability to reach near normal performance with } \\
\text { visual aids (defined in terms of low vision). }\end{array}$ & Best visual acuity $<6 / 18$ \\
\hline US Social Security Administration [17] & Ineligibility to obtain a driver’s license. & Best visual acuity < 20/40 (6/12) \\
\hline The Beaver Dam Eye Study [18] & $\begin{array}{l}\text { Inability to read a newspaper (mild impairment) or } \\
\text { to reach near normal performance with visual aids } \\
\text { (moderate impairment). }\end{array}$ & $\begin{array}{l}\text { Mild visual impairment: } \\
\text { Best visual acuity } 6 / 12 \text { to } 6 / 18 \text {; } \\
\text { Moderate visual impairment: } \\
\text { Best visual acuity }<6 / 18\end{array}$ \\
\hline Leat et al., 1999 [16] & Inability to read with near-normal fluency. & $\begin{array}{l}\text { Best visual acuity }<6 / 7.5 \text {; } \\
\text { Horizontal visual field }<146^{\circ} \text { or } 109^{\circ} \text {; } \\
\text { Contrast sensitivity }<1.5\end{array}$ \\
\hline
\end{tabular}


tral visual acuity above the criteria for visual impairment may still encounter problems related to peripheral vision or color vision in their daily lives. The measurement of this new area of health outcomes is fulfilled by questionnaires that can accurately measure people's functional statuses according to the amount of difficulty they have in performing daily activities, such as reading, writing, and walking [19]. Some instruments, such as the VF-14 [20] and Vision Screening Questionnaire [21], have been developed to measure visual functional status. These instruments are easy to administer for vision screening in large populations, allowing researchers to assess outcomes on a population-based level rather than on an individual-based level. However, the weakness of these instruments is that they may not accurately assess the severity of visual impairment in fine detail.

\subsection{Impact of Visual Impairment on Older Adults}

Visual impairment often leads to functional disabilities and is thus detrimental to people's everyday lives, especially for older adults. In particular, visual impairment affects older adults' ability to perform tasks necessary for physical self-care, thus they may need help from others. Vision loss has been ranked third (behind arthritis and heart disease) among the most common chronic conditions that impair the ability to perform daily activities among older adults aged 70 years or older [22]. Specifically, visual impairment may lead to the following problems:

a) Difficulties in activities of daily living [23] [24];

b) Falls, hip fracture and other accidents [25]-[27];

c) Social isolation and loneliness [28] [29];

d) Lower life satisfaction, anxiety, depression and suicide [30]-[33];

e) Cognitive impairment and dementia [34]-[36];

f) Increased need for residential or institutional nursing care and increased use of health care services [37][39]; and

g) Increased mortality [40]-[42].

\section{Concept of Health-Related Quality of Life (HRQOL)}

According to the WHO, health is "a state of complete physical, mental, and social well-being and not merely the absence of disease or infirmity" [43]. In other words, health not only refers to the absence of physical problems, but also includes psychological and social well-being. QOL refers to "an individual's perception on his/her life in the context of the culture and value system in which they live, and in relation to their goals, expectations, standards and concerns" [44]. It is a wide-ranging concept affected in a complex ways by the person's physical health, psychological state, level of independence, social relationships, personal beliefs, and their relationships to salient features of their environment [44]. Practically, QOL is often measured in terms of health and the term "HRQOL" is defined as "optimum levels of mental, physical, role and social functioning, including relationships, and perceptions of health, fitness, life satisfaction and well-being" [45]. Sometimes, it may include some assessments of the patient's level of satisfaction with their treatment, health status, and future prospects [45]. While many domains of HRQOL have been identified, its core dimensions generally include physical functioning, social functioning, role functioning, mental health, and general health perceptions.

\subsection{Measurement of Vision-Specific HRQOL}

Given a wide range of health problems or diseases, HRQOL may be analyzed using either generic or diseasespecific instruments. Generic instruments aim to measure multiple aspects of HRQOL; they can be applied to different populations and a range of different diseases, enabling comparison between different diseases or groups. However, generic HRQOL measures may be not as sensitive to changes in vision-related function as vision-specific questionnaires would be [46], because some HRQOL issues specific to visual problems might not be adequately represented in a generic measure [47]. In contrast, vision-specific measures can be more responsive to changes in visual problems and functional status, so they are able to discriminate more finely between the levels of severity of patients' conditions. However, vision-specific instruments are incapable of comparisons between visual impairment and other conditions [48]. The most commonly used generic instruments in the field of eye care and vision-specific HRQOL measures are listed in Table 2. More detailed information about visionspecific instruments can be found elsewhere [46] [49]. The selection of HRQOL instruments is often based on 
Table 2. Commonly used measures of visual functional status, vision-specific and generic HRQOL.

\begin{tabular}{llc}
\hline Categories & Instruments & Items \\
\hline & Activities of Daily Vision Scale (ADVS) & 22 \\
Visual functional status & Visual Activities Questionnaire (VAQ) & 33 \\
& Visual Function Index (VF-14) & 14 \\
& Visual Disability Assessment & 18 \\
& National Eye Institute Visual Function Questionnaire (NEI-VFQ) & 51 or 25 \\
Vision-specific HRQOL & Impact of Vision Impairment (IVI) & 32 \\
& Vision-Related Quality of Life Questionnaire (VQOL) & 10 \\
& Low Vision Quality of Life Questionnaire (LVQOL) & 36 or 12 \\
Generic HRQOL & Short-Form Health Survey (SF-36) & 5 \\
\hline
\end{tabular}

Adapted from Margolis et al. (2002) [46] and de Boer et al. (2004) [49]. HRQOL: health-related quality of life.

the hypothesis being tested in the study, the severity and nature of the condition or disease, and the expected benefits [50]. It is recommended that both generic and vision-specific measures are included in the same investigation to assess both clinical and broader health outcomes [45].

\subsection{Why Is HRQOL Assessment Important for Visually Impaired People?}

Visual functioning is often measured in terms of visual acuity. However, tests of visual acuity cannot capture deficits in visual functioning relating to binocular performance, reading, and driving, all of which presuppose good to excellent overall visual functioning [9]. Both performance-based and self-reported measures of visual function mainly target limitations in physical activities, and ignore mental health and extent of dependence. Thus, there is a need for multi-dimensional measures to assess the overall impact of visual impairment on health. Initially, vision-specific HRQOL instruments were devised to assess HRQOL in persons with cataracts. Researchers believed that assessing the outcomes by clinical indicators alone might underestimate the overall benefits of cataract surgery, particularly in patients with poor visual outcome [51], and that self-reported instruments might be a better measure of the benefit of cataract surgery than visual acuity [20]. Studies indicated that using a HRQOL tool rather than a functioning tool might be more informative about the impact of cataract surgery [52]. Subsequently, self-reported instruments were applied to other ocular disorders. A recent study suggested that the use of vision-specific HRQOL tools alongside anatomic outcomes provide a more comprehensive overview of patients' experiences and satisfaction after macular hole surgery [53]. Over the past two decades, multidimensional subjective measures of vision-specific HRQOL are increasingly being used as benchmarks of health outcomes in the field.

\section{Research on HRQOL of Older Adults with Visual Impairment}

As mentioned before, age-related visual impairment results from a broad spectrum of ocular disorders. To understand the overall impact of visual impairment on the HRQOL of older people, it is important to understand major age-related ocular disorders or conditions and to examine their impacts on the HRQOL of older adults. In this section, research findings on the impact of visual impairment on older adults' HRQOL are summarized by the types of ocular disorders or conditions.

\subsection{Cataracts}

Cataracts are the principal cause of visual impairment, especially in developing countries [6]. With the development of intraocular lens implantation, the visual function of patients with cataracts can be significantly improved after cataract surgery. However, access to cataract surgery is not always feasible for many older adults due to lack of adequate health insurance coverage, limitations in mobility, and other reasons. Thus, for cataract 
patients who have not yet undergone cataract surgery, HRQOL may be substantially impaired. Studies have consistently suggested that cataract surgery significantly improves vision-specific functioning and several aspects of HRQOL, and that age-related declines in health might be attenuated by improvements in visual function after cataract surgery [10] [54].

Not all cataract operations are successful and there is a small, but significant, risk of permanently reduced vision or even death following surgery [11]. Moreover, cataract operations do not consistently produce desirable visual acuity outcomes [55]. Earlier studies demonstrated that improvement in visual functioning and HRQOL after cataract extraction was observed in around $80 \%$ of patients [51] [54]. Sometimes, cataract surgery may fail to improve visual function, particularly in the cases where the patients had pre-existing ocular conditions, such as glaucoma and diabetic retinopathy, which could significantly affect outcomes following cataract surgery [11]. Moreover, some complications such as macular edema, intraocular haemorrhages and postoperative emmetropia may take place after cataract surgery, which could impede regaining adequate visual acuity. Furthermore, postoperative visual acuity may deteriorate with time. However, studies on long-term HRQOL outcomes after cataract surgery are still limited.

\subsection{Age-Related Macular Degeneration (AMD)}

AMD is a chronic, progressive, and degenerative ocular disease that leads to loss of central vision. It is prevalent in the aged population and is a major cause of moderate and severe visual impairment in developed countries [6]. The prevalence of AMD increases dramatically with age. By the age of 90 years, nearly two out of three people will have developed AMD [56]. There is not yet an effective method for treating AMD, so it remains incurable.

Existing studies consistently suggest that AMD is significantly associated with declines in functional status and HRQOL [57]-[59]. Patients with AMD are more likely than others to need help with daily activities; their ratings for HRQOL and emotional distress are significantly worse than similarly aged community-dwelling adults [57]. AMD also causes a substantial decrease in patient utility values [60].

\subsection{Glaucoma}

Glaucoma is the third leading cause of blindness among the elderly. An estimated 6.7 million people are blind because of glaucoma worldwide, with almost 70 million affected by the disease [6]. Clinical studies have indicated significant associations between glaucoma and declines in functional status and HRQOL [61]. Whereas an earlier study indicated that HRQOL in glaucoma patients is generally good when vision is intact [62], recent studies have suggested that HRQOL is reduced even in the early stages of glaucoma [63] and in persons who were previously unaware that they had glaucoma [64]. There is a clear trend of worsening HRQOL scores as glaucoma severity increases [63].

Apart from central visual impairment, glaucoma patients often experience a loss of visual field. Due to the nature of glaucoma, patients with the disease have the potential for blindness. Visual field loss in progressive glaucoma is independently associated with a loss in both disease-specific and generic HRQOL [65]. Worry about blindness has also a differential impact on HRQOL in patients with glaucoma [66]. HRQOL in newly diagnosed glaucoma patients may not be influenced by treatment [67]. Generally, glaucoma-induced visual impairment may be delayed but cannot be improved by medications and operations. Apart from impairment of central vision and peripheral vision, impairment of contrast sensitivity is significantly associated with the level of HRQOL [68] [69].

\subsection{Diabetic Retinopathy (DR)}

Diabetes is a major health problem in industrialized countries and a rapidly emerging problem in urban areas of developing countries. The world prevalence of diabetes in adults was around $6.4 \%$ in 2010, and the number of people with diabetes mellitus was projected to increase by $20 \%$ in developed countries and $69 \%$ in developing countries between 2010 and 2030 [70].

Numerous studies have documented the relationship between DR and declines in functional status and HRQOL. Greater severity of DR is associated with lower general and vision-specific HRQOL [71]-[73]. Persons with bilateral moderate DR have the most substantial decrease in HRQOL compared with those with less severe DR [74]. Klein and colleages [75] reported that the HRQOL of patients with DR seemed to be strongly associated with vision, independent of severity of retinopathy and other complications associated with diabetes. 
Long-term follow-up or longitudinal studies also suggested that changes in visual acuity were the most important factor associated with corresponding changes in HRQOL scores in individuals with DR [73] [76]. At similar levels of visual acuity loss, DR appears to cause a similar reduction in HRQOL as AMD [71]. Another study indicated that HRQOL in patients with DR was correlated with contrast sensitivity in addition to visual acuity [77].

\subsection{Uncorrected Refractive Errors}

Uncorrected refractive errors are also a leading cause of visual impairment in the elderly [78]. It is estimated that 153 million people are visually impaired due to uncorrectable refractive errors [79] and an additional 517 million have uncorrected or under-corrected presbyopia [80]. A study in Australia found that refractive errors were responsible for one quarter of "legal blindness" and half of moderate visual impairments [81]. Another study reported that refractive impairments accounted for over 3/4 of presenting bilateral visual impairments [82].

Presbyopia is an important form of refractive error and is very common among older adults. Existing studies indicate that declines in functional status and HRQOL are related to presbyopia or age-related refractive errors [83]. Difficulties with activities of daily living and resulting social impediments are common among older adults due to presbyopia [84]. Not only does uncorrected presbyopia have a significant impact on HRQOL [85] [86], but presbyopia corrected with glasses is also associated with a nominal decrease in HRQOL [87].

\subsection{Unilateral Visual Impairment}

In many age-related ocular disorders such as AMD, glaucoma and DR, it is rare for both eyes of the patients to be equally affected at the same time. Thus, unilateral visual impairment is common among the aged population. The impact of unilateral visual impairment on HRQOL has received attention in recent years. It has been suggested that moderate to severe non-correctable unilateral visual impairment has a measurable impact on HRQOL, even when good visual acuity is maintained in the uninvolved eye [88]-[90]. For people whose visual acuity is reduced to different degrees for both eyes, it is the better-eye acuity that is associated with a decrease in most domains of HRQOL [85] [89] [91]. However, preserving minimal visual acuity in the worst eye might contribute to HRQOL [58]. Usually, patients with bilateral visual impairment have worse HRQOL than patients with unilateral visual impairment [92]. It is suggested that unilateral vision loss is associated with issues of safety and independent living while bilateral vision loss is associated with orientation, nursing home placement, use of community services, and emotional well-being [93].

\subsection{Blindness}

Blindness is the end of visual impairment. It is reported that more than $82 \%$ of all blind people are 50 years and older [1]. Although many studies have documented the impact of blindness on depression and psychological well-being, studies on the impact of blindness on HRQOL are still limited. One study suggested that overall HRQOL score is unacceptably low for those severely blind, compared with normally sighted individuals [94]. Another study suggested that people who were blind due to glaucoma had lower visual function and HRQOL scores than those who were blind due to cataracts [95].

\subsection{Brief Summary}

To sum up, various aged-related ocular disorders may result in decline in visual function, and thus have significant effects on patients' HRQOL. It is the level of vision loss rather than the specific disease process causing reduced vision that is associated with decreases in most domains of HRQOL [96] [97]. Even mild visual impairment is independently associated with poor HRQOL [98]. In addition, different ocular disorders have differing impacts on HRQOL. In those with cataracts, low acuity explains most of the low HRQOL scores, but those with glaucoma or diabetic retinopathy have low scores on HRQOL not explained by loss of acuity [85]. Generally, reductions in HRQOL do not occur at earlier stages of age-related ocular diseases or as long as vision is intact [62] [99]. The period of time over which the visual loss occurs is not related to the HRQOL of older adults [100]. Regardless of treatment, improvements in HRQOL functions generally occur when visual acuity improves; thus, many types of functional degeneration attributed to a decline in vision in older populations could be slowed or even reversed when visual acuity is improved [101]. 


\section{Factors Influencing HRQOL}

To improve or maintain HRQOL for older people in general and visually impaired older adults in particular is an important goal of both health care and social care. As addressed before, many types of functional degeneration attributed to a decline in vision can be slowed or even reversed, subsequently improving the older adults' HRQOL when visual acuity is improved. It has been confirmed that early detection and treatment of age-related ocular disorders can reduce the progression of the disease or the onset of vision loss, and prevent blindness [102]. Monitoring the progression of ocular diseases and long-term follow-ups are important for avoiding the development of long-term complications and deterioration of patients' visual function, thus promoting their HRQOL [55] [74] [76]. Therefore, accessible and affordable eye care is particular important for improving the HRQOL of visually impaired older adults. Unfortunately, unaddressed visual problems are common among the general older population and nursing home population. A recent survey conducted in 70 countries indicated the rate of eye care utilization by older adults was $37 \%$ in high income countries and only $10 \%$ in low income countries [103].

Low-vision rehabilitation services, which mainly focus on various optical and non-optical devices and techniques to enhance residual vision or substitute for lost vision, is important in helping people regain their independence, take care of personal needs, and participate in work/leisure activities [104]. Studies have suggested that appropriate rehabilitation can significantly improve HRQOL for visually impaired patients including those with glaucoma [83] [105] and the oldest old [106]. However, it has been suggested that the present system of low-vision care is less than optimal in many countries, and that only $10 \%-15 \%$ of visually impaired people can access low-vision services [107]. Thus, meeting the eye care needs of older people is still a major challenge for many countries. In such situations, it would be important to understand what factors beyond medical treatment and vision rehabilitation influence HRQOL of visually impaired older adults, as it would be helpful for improving their HRQOL.

\subsection{Age}

While one study suggested that age did not significantly affect global QOL [108], two studies suggested that age was independently associated with vision-specific QOL impairment [109] [110]. A study suggested that there was a significant interaction effect of vision status and age on life satisfaction and QOL [111].

\subsection{Gender}

Vision loss is more frequently observed in women than in men [3]. Although one study suggested that HRQOL was worse in women than in men for all categories of impaired visual acuity [112], another study did not [110].

\subsection{Socioeconomic Status}

A very high rate of visual impairment is often observed in the low socioeconomic status population [113]. It was reported that socioeconomic resources, measured as income and financial strain, played a role in explaining the effect of visual impairment on declines in people's HRQOL [31], and that increasing material deprivation was independently associated with reduced levels of vision-specific HRQOL [109].

\subsection{Mobility}

It was found that the ability to get around made a significant and unique contribution to the prediction of perceived HRQOL [114]. Activity limitations played a role in explaining the effect of visual impairment on declines in HRQOL [31]. Higher perceived activity levels appear to predict better HRQOL [115].

\subsection{Comorbidity}

Comorbidity is the presence of one or more additional disorders such as hearing impairment, asthma, arthritis, cancer or diabetes, in the presence of visual impairment. Comorbidity is common among older adults and is considered a major threat to HRQOL. One study indicated that the presence of comorbidity predicted a relatively rapid decline in the HRQOL of visually impaired older patients [116]. Another study reported that the presence of comorbidities lead to significant impairments in both the physical and mental components of HRQOL 
[117]. While an earlier study reported that the number of associated systemic comorbidities did not significantly affect HRQOL [118], recent studies found that the number of diagnosed comorbidities could significantly predict perceived HRQOL [114] [115]. However, the negative impact of visual impairments on HRQOL was not exacerbated by the co-occurrence of cognitive impairments [119].

\subsection{Family Support}

Due to functional disabilities, visually impaired older adults often need help from others especially family members. Previous studies have indicated that both emotional and instrumental support provided by family members be important to the HRQOL of older adults with visual impairment [120] [121]. A recent study on marital quality of older adults suggests that relationship satisfaction and supportive spouse behaviors moderate the effects of poor vision on functional limitations and depressive symptoms [122].

\subsection{Social Support}

Many visually impaired older adults have reduced social networks due to their limited capacity to participate in social activities [28]. Social support has emerged as one of the most important contributors to HRQOL for people with visual impairments [111]. Researchers have reported that participation in social roles, social integration, and perceived support play roles in explaining the effect of visual impairment on declines in the HRQOL of older adults [31] [115]. Severely visually impaired older adults may feel being isolated from society and experience decreases in social status. Decreased social status is independently associated with HRQOL impairments [109]. Thus, support groups and peer counseling can be extremely helpful for older adults with visual impairments in coping with vision loss [123]. Studies indicated that friendship networks [28], friendship support [121], the reassurance of one's worth by friends and the enjoyment of companionship from friends [120] were significantly associated with better adaptation, psychological well-being and HRQOL, independent of family network and family support, in visually impaired older adults. A study further suggested that high qualitative friend support and high quantitative family support were significantly associated better adaptation to vision loss among older adults [120].

\subsection{Use of Eye Care Services}

A cross-sectional study documented that only $16 \%$ of older persons with treatable visual impairments were under eye care at the time of study, and that a significant number of older adults had not undergone eye examination for more than 3 years [124]. Thus, use of eye care service is an important factor that may influence visually impaired older adults' HRQOL. Studies have shown that older adults in contact with eye care services have more positive scores on general health perceptions, vitality/energy, and mental health after controlling for all other covariates [125]. A study also reported that use of a writing aid predicted better HRQOL [115].

\subsection{Psychological and Spiritual Factors}

For an older person who has had full sight until late life, the onset of a visual impairment may be a profound experience and often requires considerable psychosocial and functional adjustment. Researchers found that psychosocial adaptation status as a process was significantly associated with vision-specific HRQOL [126] [127]. Psychosocial adaptation status could also buffer the effect of visual impairment on domains of HRQOL [126]. Brown \& Barrett [29] reported that psychological resources (self-efficacy) played a role in explaining the effect of visual impairment on declines in HRQOL. Another study suggested that spirituality was significantly associated with domains of vision-specific HRQOL [128].

\section{Problems and Recommendations}

\subsection{Insufficient Attention to Vision-Specific HRQOL Research in Non-Medical Settings}

According to the American Ophthalmologic Association's guidelines, older adults should undertake a comprehensive eye exam each year; however, there seems a disconnection between ophthalmologic recommendations and what is actually occurring in nursing homes where visual impairment is rarely assessed [129]. To date, the majority of vision-specific HRQOL research has been conducted in medical settings and focused on particular visual disorders. Only in recent years has attention been paid to HRQOL of visually impaired older adults in 
communities and home care settings. The precise psychosocial and environmental factors that may contribute to vision-specific HRQOL of older adults or mediate/buffer the impact of visual impairment on their HRQOL are far from clear. More attention should be paid to this area of study.

\subsection{Cross-Cultural Reliability and Validity of Vision-Specific HRQOL Measures}

Currently, the majority of the scales assessing vision-specific HRQOL originate in the United States and Europe. Some indicators in the instruments may not be suitable for people in other cultural contexts. There is a need for these scales to be culturally adapted and modified in order to improve the quality of assessment. Another issue is that HRQOL as a multidimensional concept is often interpreted through diverse methods and measured by a range of instruments in the field of eye health. Thus, the best way to measure or explore vision-specific HRQOL should be determined.

\subsection{Practical Problems with HRQOL Measurement in Visually Impaired Older Adults}

Because of the self-report nature of HRQOL measurement, researchers evaluating HRQOL among older adults may encounter some difficulties. Several methodological problems of HRQOL evaluation in older patients with cancer have already been summarized elsewhere [130]; these problems may also be applicable to patients with visual impairment, which include: (1) a higher proportion of illiteracy in older adults as compared with younger patients; (2) cognitive impairments leading to difficulty in understanding HRQOL questionnaires; (3) presence of comorbidities that potentially confuse the real impact of visual impairment on HRQOL; and (4) HRQOL evaluation can be complicated by poor eyesight, hearing difficulties, fatigue, and poor performance status. In these situations, researchers might consider using the reports of proxies or care givers to evaluate the older adults' HRQOL [130].

\subsection{Limited Number of Intervention Studies to Offer Insights for Improving Visually Impaired Older Adults' HRQOL}

With increasing number of visually impaired older people and the significant impact of visual impairment on their HRQOL, there is an increasing interest in identifying ways for promoting higher levels of HRQOL in old age, especially for those with severe visual impairment. To date, randomized controlled trials of interventional strategies aiming to promote visually impaired older adults' HRQOL are still rare. Only a very few interventional studies for visually impaired older adults can be identified in the literature. A study reported that tailored self-management programs could enhance well-being in older persons with poor eyesight due to AMD [131]. Another study assessed the efficacy of a home safety program and a home exercise program to reduce falls and injuries in older people with low vision [132]. An additional study investigated the impact of a health education program on perceived security in the performance of daily activities among older persons with visual impairment [133]. A recent study examined the effects of Tai Chi on the balance control of older persons with visual impairment [134]. Thus, more interventional studies are warranted in this area to set a foundation for evidence-based practice to improve visually impaired older adults' HRQOL.

\section{Conclusion}

HRQOL is currently an often discussed and used outcome in gerontology. Although it is a multi-dimensional concept, it can be seen from a holistic perspective. To date, a number of studies have documented the relationship between different types of ocular disorders or conditions and deterioration in the HRQOL of older adults, but the number of studies aiming at enhancing the HRQOL of visually impaired older people is limited. Given that visual impairment is prevalent among the older population and that visually impaired older adults' needs for eye care and vision rehabilitation are greatly unmet, interventions that may enhance the HRQOL of visually impaired older people are valued. There is a need for further research to refine the strategies of creating, implementing, maintaining, and evaluating community-based multidisciplinary programs aiming to improve the HRQOL of older adults with visual impairment.

\section{Conflict of Interest}

All authors declare no conflict of interest. 


\section{References}

[1] Resnikoff, S., Pascolini, D., Etya’ale, D., Kocur, I., Pararajasegaram, R., Pokharel, G.P., et al. (2004) Global Data on Visual Impairment in the Year 2002. Bulletin of the World Health Organization, 82, 844-851.

[2] Taylor, H.R. and Keeffe, J.E. (2001) World Blindness: A 21st Century Perspective. British Journal of Ophthalmology, 85, 261-266. http://dx.doi.org/10.1136/bjo.85.3.261

[3] Dey, A. (1997) Characteristics of Older Nursing Home Residents: Data from the 1995 National Nursing Home Survey. Advance Data from Vital and Health Statistics, No. 289. National Center for Health Statistics, Hyattsville.

[4] Evans, B.J. and Rowlands, G. (2004) Correctable Visual Impairment in Older People: A Major Unmet Need. Ophthalmic and Physiological Optics, 24, 161-180. http://dx.doi.org/10.1111/j.1475-1313.2004.00197.x

[5] Michon, J.J., Lau, J., Chan, W.S. and Ellwein, L.B. (2002) Prevalence of Visual Impairment, Blindness, and Cataract Surgery in the Hong Kong Elderly. British Journal of Ophthalmology, 86, 133-139. http://dx.doi.org/10.1136/bjo.86.2.133

[6] Congdon, N.G., Friedman, D.S. and Lietman, T. (2003) Important Causes of Visual Impairment in the World Today. JAMA, 290, 2057-2060. http://dx.doi.org/10.1001/jama.290.15.2057

[7] Mills, T., Law, S.K., Walt, J., Buchholz, P. and Hansen, J. (2009) Quality of Life in Glaucoma and Three Other Chronic Diseases: A Systematic Literature Review. Drugs and Aging, 26, 933-950. http://dx.doi.org/10.2165/11316830-000000000-00000

[8] Mitchell, J. and Bradley, C. (2006) Quality of Life in Age-Related Macular Degeneration: A Review of the Literature. Health and Quality of Life Outcomes, 4, 97. http://dx.doi.org/10.1186/1477-7525-4-97

[9] Chakravarthy, U. and Stevenson, M. (2005) Self-Reported Visual Functioning and Quality of Life in Age-Related Macular Degeneration. Current Opinion in Ophthalmology, 16, 179-183. http://dx.doi.org/10.1097/01.icu.0000163035.37957.c2

[10] Lamoureux, E.L., Fenwick, E., Pesudovs, K. and Tan, D. (2011) The Impact of Cataract Surgery on Quality of Life. Current Opinion in Ophthalmology, 22, 19-27. http://dx.doi.org/10.1097/ICU.0b013e3283414284

[11] Morris, D., Fraser, S.G. and Gray, C. (2007) Cataract Surgery and Quality of Life Implications. Clinical Interventions in Aging, 2, 105-108. http://dx.doi.org/10.2147/ciia.2007.2.1.105

[12] Sharma, S., Oliver-Fernandez, A., Liu, W., Buchholz, P. and Walt, J. (2005) The Impact of Diabetic Retinopathy on Health-Related Quality of Life. Current Opinion in Ophthalmology, 16, 155-159. http://dx.doi.org/10.1097/01.icu.0000161227.21797.3d

[13] Spaeth, G., Walt, J. and Keener, J. (2006) Evaluation of Quality of Life for Patients with Glaucoma. American Journal of Ophthalmology, 141, S3-S14. http://dx.doi.org/10.1016/j.ajo.2005.07.075

[14] Denniston, A.K. and Philip, I.M. (2009) Oxford Handbook of Ophthalmology. Oxford University Press, Oxford. http://dx.doi.org/10.1093/med/9780199552641.001.0001

[15] World Health Organization (1980) International Classification of Impairments, Disabilities and Handicaps: A Manual of Classification Relating to the Consequences of Disease. World Health Organization, Geneva.

[16] Leat, S.J., Legge, G.E. and Bullimore, M.A. (1999) What Is Low Vision? A Re-Evaluation of Definitions. Optometry \& Vision Science, 76, 198-211. http://dx.doi.org/10.1097/00006324-199904000-00023

[17] Rubin, G.S., West, S.K., Munoz, B., Bandeen-Roche, K., Zeger, S., Schein, O., et al. (1997) A Comprehensive Assessment of Visual Impairment in a Population of Older Americans. The SEE Study. Salisbury Eye Evaluation Project. Investigative Ophthalmology \& Visual Science, 38, 557-568.

[18] Klein, R., Klein, B.E., Linton, K.L. and De Mets, D.L. (1991) The Beaver Dam Eye Study: Visual Acuity. Ophthalmology, 98, 1310-1315. http://dx.doi.org/10.1016/S0161-6420(91)32137-7

[19] McDowell, I. (2006) Measuring Health: A Guide to Rating Scales and Questionnaires. 3rd Edition, Oxford University Press, New York. http://dx.doi.org/10.1093/acprof:oso/9780195165678.001.0001

[20] Steinberg, E.P., Tielsch, J.M., Schein, O.D., Javitt, J.C., Sharkey, P., Cassard, S.D., et al. (1994) The VF-14. An Index of Functional Impairment in Patients with Cataract. Archives of Ophthalmology, 112, 630-638. http://dx.doi.org/10.1001/archopht.1994.01090170074026

[21] Horowitz, A., Teresi, J. and Cassels, L.A. (1991) Development of a Vision Screening Questionnaire for Older People. Journal of Gerontological Social Work, 17, 37-56. http://dx.doi.org/10.1300/J083v17n03 04

[22] LaPlante, M. and Carlson, D. (1996) Disability in the United States: Prevalence and Causes, 1992. Disability Statistics Report (7). U.S. Department of Education, National Institute on Disability and Rehabilitation Research, Washington DC.

[23] Kelly, M. (1995) Consequences of Visual Impairment on Leisure Activities of the Elderly. Geriatric Nursing, 16, 273- 
275. http://dx.doi.org/10.1016/S0197-4572(95)80008-5

[24] Haymes, S.A., Johnston, A.W. and Heyes, A.D. (2002) Relationship between Vision Impairment and Ability to Perform Activities of Daily Living. Ophthalmic \& Physiological Optics, 22, 79-91. http://dx.doi.org/10.1046/j.1475-1313.2002.00016.x

[25] Patino, C.M., McKean-Cowdin, R., Azen, S.P., Allison, J.C. Choudhury, F., Varma, R., et al. (2010) Central and Peripheral Visual Impairment and the Risk of Falls and Falls with Injury. Ophthalmology, 117, 199-206.

[26] Ivers, R.Q., Cumming, R.G., Mitchell, P. and Attebo, K. (1998) Visual Impairment and Falls in Older Adults: The Blue Mountains Eye Study. Journal of American Geriatrics Society, 46, 58-64.

[27] Lopez, D., McCaul, K.A., Hankey, G.J., Norman, P.E., Almeida, O.P., Dobson, A.J., et al. (2011) Falls, Injuries from Falls, Health Related Quality of Life and Mortality in Older Adults with Vision and Hearing Impairment-Is There a Gender Difference? Maturitas, 69, 359-364. http://dx.doi.org/10.1016/j.maturitas.2011.05.006

[28] Wang, C.W., Chan, C.L., Ho, A.H. and Xiong, Z. (2008) Social Networks and Health-Related Quality of Life among Chinese Older Adults with Vision Impairment. Journal of Aging and Health, 20, 804-823. http://dx.doi.org/10.1177/0898264308321083

[29] Holmen, K., Andersson, L., Ericsson, K., Rydberg, L. and Winblad, B. (1994) Visual Impairment Related to Cognition and Loneliness in Old-Age. Scandinavian Journal of Caring Sciences, 8, 99-105. http://dx.doi.org/10.1111/j.1471-6712.1994.tb00236.x

[30] Renaud, J. and Bédard, E. (2013) Depression in the Elderly with Visual Impairment and Its Association with Quality of Life. Clinical Interventions in Aging, 8, 931-943. http://dx.doi.org/10.2147/CIA.S27717

[31] Brown, R.L. and Barrett, A.E. (2011) Visual Impairment and Quality of Life among Older Adults: An Examination of Explanations for the Relationship. The Journals of Gerontology. Series B, Psychological Sciences and Social Sciences, 66, 364-373. http://dx.doi.org/10.1093/geronb/gbr015

[32] De Leo, D., Hickey, P.A., Meneghel, G. and Cantor, C.H. (1999) Blindness, Fear of Sight Loss, and Suicide. Psychosomatics, 40, 339-344. http://dx.doi.org/10.1016/S0033-3182(99)71229-6

[33] Mathew, R.S., Delbaere, K., Lord, S.R., Beaumont, P., Vaegan, and Madigan, M.C. (2011) Depressive Symptoms and Quality of Life in People with Age-Related Macular Degeneration. Ophthalmic and Physiological Optics, 31, 375-380. http://dx.doi.org/10.1111/j.1475-1313.2011.00848.x

[34] Wood, J., Chaparro, A., Anstey, K., Lacherez, P. Chidgey, A., Eisemann, J., et al. (2010) Simulated Visual Impairment Leads to Cognitive Slowing in Older Adults. Optometry \& Vision Science, 87, 1037-1043. http://dx.doi.org/10.1097/OPX.0b013e3181fe64d7

[35] Ong, S.Y., Cheung, C.Y., Li, X, Lamoureux, E.L., Ikram, M.K., Ding, J., et al. (2012) Visual Impairment, Age-Related Eye Diseases, and Cognitive Function: The Singapore Malay Eye Study. Archives of Ophthalmology, 130, 895-900. http://dx.doi.org/10.1001/archophthalmol.2012.152

[36] Lawrence, V., Murray, J., Ffytche, D. and Banerjee, S. (2009) “Out of Sight, Out of Mind”: A Qualitative Study of Visual Impairment and Dementia from Three Perspectives. International Psychogeriatrics, 21, 511-518. http://dx.doi.org/10.1017/S1041610209008424

[37] Tay, T., Wang, J.J., Lindley, R., Chia, E.M., Landau, P., Ingham, N., et al. (2007) Sensory Impairment, Use of Community Support Services, and Quality of Life in Aged Care Clients. Journal of Aging \& Health, 19, 229-241. http://dx.doi.org/10.1177/0898264307299243

[38] Wang, J.J., Mitchell, P., Cumming, R.G. and Smith, W. (2003) Visual Impairment and Nursing Home Placement in Older Australians: The Blue Mountains Eye Study. Ophthalmic Epidemiology, 10, 3-13. http://dx.doi.org/10.1076/opep.10.1.3.13773

[39] Evans, J.R., Smeeth, L. and Fletcher, A.E. (2008) Risk of Admission to a Nursing Home among Older People with Visual Impairment in Great Britain. Archives of Ophthalmology, 126, 1428-1433. http://dx.doi.org/10.1001/archopht.126.10.1428

[40] Karpa, M.J., Mitchell, P., Beath, K., Rochtchina, E., Cumming, R.G., Wang, J.J., et al. (2009) Direct and Indirect Effects of Visual Impairment on Mortality Risk in Older Persons. Archives of Ophthalmology, 127, 1347-1353. http://dx.doi.org/10.1001/archophthalmol.2009.240

[41] Lee, D.J., Gomez-Marin, O., Lam, B.L. and Zheng, D.D. (2002) Visual Acuity Impairment and Mortality in US Adults. Archives of Ophthalmology, 120, 1544-1550. http://dx.doi.org/10.1001/archopht.120.11.1544

[42] Jacobs, J.M., Hammerman-Rozenberg, R., Maaravi, Y., Cohen, A. and Stessman, J. (2005) The Impact of Visual Impairment on Health, Function and Mortality. Aging Clinical and Experimental Research, 17, 281-286. http://dx.doi.org/10.1007/BF03324611

[43] World Health Organization (1948) Official Records of the World Health Organization. No. 2, WHO, Geneva, 100. 
[44] World Health Organization Quality of Life Assessment Group (1995) The World Health Organization Quality of Life Assessment (WHOQOL): Position Paper from the World Health Organization. Social Science and Medicine, 41, 1403-1409. http://dx.doi.org/10.1016/0277-9536(95)00112-K

[45] Bowling, A. (2001) Health-Related Quality of Life: Conceptual Meaning, Use and Measurement. In: Bowling, A., Ed., Measuring Disease: A Review of Disease-Specific Quality of Life Measurement Scales, 2nd Edition, Open University Press, Buckingham.

[46] Margolis, M.K., Coyne, K., Kennedy-Martin, T., Baker, T., Schein, O. and Revicki, D.A. (2002) Vision-Specific Instruments for the Assessment of Health-Related Quality of Life and Visual Functioning: A Literature Review. Pharmacoeconomics, 20, 791-812. http://dx.doi.org/10.2165/00019053-200220120-00001

[47] Lee, J.E., Fos, P.J., Zuniga, M.A., Kastl, P.R. and Sung, J.H. (2000) Assessing Health-Related Quality of Life in Cataract Patients: The Relationship between Utility and Health-Related Quality of Life Measurement. Quality of Life Research, 9, 1127-1135. http://dx.doi.org/10.1023/A:1016645523769

[48] Patrick, D.L. and Deyo, R.A. (1989) Generic and Disease-Specific Measures in Assessing Health Status and Quality of Life. Medical Care, 27, S217-232. http://dx.doi.org/10.1097/00005650-198903001-00018

[49] de Boer, M.R., Moll, A.C., de Vet, H.C., Terwee, C.B., Volker-Dieben, H.J. and van Rens, G.H. (2004) Psychometric Properties of Vision-Related Quality of Life Questionnaires: A Systematic Review. Ophthalmic and Physiological Optics, 24, 257-273. http://dx.doi.org/10.1111/j.1475-1313.2004.00187.x

[50] Cramer, J.A. and ILAE Subcommission on Outcome Measurement in Epilepsy (2002) Principles of Health-Related Quality of Life: Assessment in Clinical Trials. Epilepsia, 43, 1084-1095. http://dx.doi.org/10.1046/j.1528-1157.2002.47501.x

[51] Desai, P., Reidy, A., Minassian, D.C., Vafidis, G. and Bolger, J. (1996) Gains from Cataract Surgery: Visual Function and Quality of Life. British Journal of Ophthalmology, 80, 868-873. http://dx.doi.org/10.1136/bjo.80.10.868

[52] Lamoureux, E.L., Hooper, C.Y., Lim, L., Pallant, J.F., Hunt, N., Keeffe, J.E., et al. (2007) Impact of Cataract Surgery on Quality of Life in Patients with Early Age-Related Macular Degeneration. Optometry \& Vision Science, 84, 683688. http://dx.doi.org/10.1097/OPX.0b013e31812f755f

[53] Rayat, J., Almeida, D.R., Belliveau, M., Wong, J. and Gale, J. (2011) Visual Function and Vision-Related Quality of Life after Macular Hole Surgery with Short-Duration, 3-Day Face-Down Positioning. Canada Journal of Ophthalmology, 46, 399-402. http://dx.doi.org/10.1016/j.jcjo.2011.07.015

[54] Mangione, C.M., Phillips, R.S., Lawrence, M.G., Seddon, J.M., Orav, E.J. and Goldman, L. (1994) Improved Visual Function and Attenuation of Declines in Health-Related Quality of Life after Cataract Extraction. Archives of Ophthalmology, 112, 1419-1425. http://dx.doi.org/10.1001/archopht.1994.01090230033017

[55] Lau, J., Michon, J.J., Chan, W.S. and Ellwein, L.B. (2002) Visual Acuity and Quality of Life Outcomes in Cataract Surgery Patients in Hong Kong. British Journal of Ophthalmology, 86, 12-17. http://dx.doi.org/10.1136/bjo.86.1.12

[56] VanNewkirk, M.R., Nanjan, M.B., Wang, J.J., Mitchell, P., Taylor, H.R. and McCarty, C.A. (2000) The Prevalence of Age-Related Maculopathy: The Visual Impairment Project. Ophthalmology, 107, 1593-1600. http://dx.doi.org/10.1016/S0161-6420(00)00175-5

[57] Williams, R.A., Brody, B.L., Thomas, R.G., Kaplan, R.M. and Brown, S.I. (1998) The Psychosocial Impact of Macular Degeneration. Archives of Ophthalmology, 116, 514-520. http://dx.doi.org/10.1001/archopht.116.4.514

[58] Berdeaux, G.H., Nordmann, J.P., Colin, E. and Arnould, B. (2005) Vision-Related Quality of Life in Patients Suffering from Age-Related Macular Degeneration. American Journal of Ophthalmology, 139, 271-279. http://dx.doi.org/10.1016/j.ajo.2004.09.028

[59] Siaudvytyte, L., Mitkute, D. and Balciuniene, J. (2012) Quality of Life in Patients with Age-Related Macular Degeneration. Medicina (Kaunas), 48, 109-111.

[60] Brown, G.C., Sharma, S., Brown, M.M. and Kistler, J. (2000) Utility Values and Age-Related Macular Degeneration. Archives of Ophthalmology, 118, 47-51. http://dx.doi.org/10.1001/archopht.118.1.47

[61] Parrish, R.K., Gedde, S.J., Scott, I.U., Feuer, W.J., Schiffman, J.C., Mangione, C.M., et al. (1997) Visual Function and Quality of Life among Patients with Glaucoma. Archives of Ophthalmology, 115, 1447-1455. http://dx.doi.org/10.1001/archopht.1997.01100160617016

[62] Wandell, P.E., Lundstrom, M., Brorsson, B. and Aberg, H. (1997) Quality of Life among Patients with Glaucoma in Sweden. Acta Ophthalmologica Scandinavica, 75, 584-588. http://dx.doi.org/10.1111/j.1600-0420.1997.tb00154.x

[63] Onakoya, A.O., Mbadugha, C.A., Aribaba, O.T. and Ibidapo, O.O. (2012) Quality of Life of Primary Open Angle Glaucoma Patients in Lagos, Nigeria: Clinical and Sociodemographic Correlates. Journal of Glaucoma, 21, 287-295. http://dx.doi.org/10.1097/IJG.0b013e31820d7cfd

[64] McKean-Cowdin, R., Wang, Y., Wu, J., Azen, S.P., Varma, R. and Los Angeles Latino Eye Study Group (2008) Im- 
pact of Visual Field Loss on Health-Related Quality of Life in Glaucoma: The Los Angeles Latino Eye Study. Ophthalmology, 115, 941-948.

[65] van Gestel, A., Webers, C.A., Beckers, H.J, van Dongen, M.C., Severens, J.L., Hendrikse, F., et al. (2010) The Relationship between Visual Field Loss in Glaucoma and Health-Related Quality-of-Life. Eye (Lond), 24, 1759-1769. http://dx.doi.org/10.1038/eye.2010.133

[66] Evans, K., Law, S.K., Walt, J., Buchholz, P. and Hansen, J. (2009) The Quality of Life Impact of Peripheral versus Central Vision Loss with a Focus on Glaucoma versus Age-Related Macular Degeneration. Clinical Ophthalmology, 3, 433-445. http://dx.doi.org/10.2147/OPTH.S6024

[67] Hyman, L.G., Komaroff, E., Heijl, A., Bengtsson, B., Leske, M.C. and Early Manifest Glaucoma Trial Group (2005) Treatment and Vision-Related Quality of Life in the Early Manifest Glaucoma Trial. Ophthalmology, 112, 1505-1513. http://dx.doi.org/10.1016/j.ophtha.2005.03.028

[68] Bansback, N., Czoski-Murray, C., Carlton, J., Lewis, G., Hughes, L., Espallargues, M., et al. (2007) Determinants of Health Related Quality of Life and Health State Utility in Patients with Age Related Macular Degeneration: The Association of Contrast Sensitivity and Visual Acuity. Quality of Life Research, 16, 533-543. http://dx.doi.org/10.1007/s11136-006-9126-8

[69] Leung, J.C., Kwok, T.C., Chan, D.C., Yuen, K.W., Kwok, A.W., Choy, D.T., et al. (2012) Visual Functioning and Quality of Life among the Older People in Hong Kong. International Journal of Geriatric Psychiatry, 27, 807-815. http://dx.doi.org/10.1002/gps.2789

[70] Shaw, J.E., Sicree, R.A. and Zimmet, P.Z. (2010) Global Estimates of the Prevalence of Diabetes for 2010 and 2030. Diabetes Research and Clinical Practice, 87, 4-14. http://dx.doi.org/10.1016/j.diabres.2009.10.007

[71] Brown, M.M., Brown, G.C., Sharma, S., Landy, J. and Bakal, J. (2002) Quality of Life with Visual Acuity Loss from Diabetic Retinopathy and Age-Related Macular Degeneration. Archives of Ophthalmology, 120, 481-484. http://dx.doi.org/10.1001/archopht.120.4.481

[72] Fenwick, E.K., Xie, J., Ratcliffe, J., Pesudovs, K., Finger, R.P., Wong, T.Y., et al. (2012) The Impact of Diabetic Retinopathy and Diabetic Macular Edema on Health-Related Quality of Life in Type 1 and Type 2 Diabetes. Investigative Ophthalmology \& Visual Science, 53, 677-684. http://dx.doi.org/10.1167/iovs.11-8992

[73] Matza, L.S., Rousculp, M.D., Malley, K., Boye, K.S. and Oglesby, A. (2008) The Longitudinal Link between Visual Acuity and Health-Related Quality of Life in Patients with Diabetic Retinopathy. Health and Quality of Life Outcomes, 6, 95. http://dx.doi.org/10.1186/1477-7525-6-95

[74] Mazhar, K., Varma, R., Choudhury, F., McKean-Cowdin, R., Shtir, C.J., Azen, S.P., et al. (2011) Severity of Diabetic Retinopathy and Health-Related Quality of Life: The Los Angeles Latino Eye Study. Ophthalmology, 118, 649-655. http://dx.doi.org/10.1016/j.ophtha.2010.08.003

[75] Klein, R., Moss, S.E., Klein, B.E., Gutierrez, P. and Mangione, C.M. (2001) The NEI-VFQ-25 in People with LongTerm Type 1 Diabetes Mellitus: The Wisconsin Epidemiologic Study of Diabetic Retinopathy. Archives of Ophthalmology, 119, 733-740. http://dx.doi.org/10.1001/archopht.119.5.733

[76] Hirai, F.E., Tielsch, J.M., Klein, B.E. and Klein, R. (2011) Ten-Year Change in Vision-Related Quality of Life in Type 1 Diabetes: Wisconsin Epidemiologic Study of Diabetic Retinopathy. Ophthalmology, 118, 353-358. http://dx.doi.org/10.1016/j.ophtha.2010.06.022

[77] Okamoto, F., Okamoto, Y., Fukuda, S., Hiraoka, T. and Oshika, T. (2008) Vision-Related Quality of Life and Visual Function Following Vitrectomy for Proliferative Diabetic Retinopathy. American Journal of Ophthalmology, 145, 1031-1036. http://dx.doi.org/10.1016/j.ajo.2008.02.006

[78] Evans, J.R., Fletcher, A.E. and Wormald, R.P.L. (2004) Causes of Visual Impairment in People Aged 75 Years and Older in Britain: An Add-On Study to the MRC Trial of Assessment and Management of Older People in the Community. British Journal of Ophthalmology, 88, 365-370. http://dx.doi.org/10.1136/bjo.2003.019927

[79] Resnikoff, S., Pascolini, D., Mariotti, S.P. and Pokharel, G.P. (2008) Global Magnitude of Visual Impairment Caused by Uncorrected Refractive Errors in 2004. Bulletin of the World Health Organization, 86, 63-70. http://dx.doi.org/10.2471/BLT.07.041210

[80] Holden, B.A., Fricke, T.R., Ho, S.M., Wong, R., Schlenther, G., Cronjé, S., et al. (2008) Global Vision Impairment Due to Uncorrected Presbyopia. Archives of Ophthalmology, 126, 1731-1739. http://dx.doi.org/10.1001/archopht.126.12.1731

[81] Weih, L.M., VanNewkirk, M.R., McCarty, C.A. and Taylor, H.R. (2000) Age-Specific Causes of Bilateral Visual Impairment. Archives of Ophthalmology, 118, 264-269. http://dx.doi.org/10.1001/archopht.118.2.264

[82] Chia, E.M., Mitchell, P., Ojaimi, E., Rochtchina, E. and Wang, J.J. (2006) Assessment of Vision-Related Quality of Life in an Older Population Subsample: The Blue Mountains Eye Study. Ophthalmic Epidemiology, 13, 371-377. http://dx.doi.org/10.1080/09286580600864794 
[83] McDonnell, P.J., Lee, P., Spritzer, K., Lindblad, A.S. and Hays, R.D. (2003) Associations of presbyopia with VisionTargeted Health-Related Quality of Life. Archives of Ophthalmology, 121, 1577-1581. http://dx.doi.org/10.1001/archopht.121.11.1577

[84] Lu, Q., Congdon, N., He, X., Murthy, G.V., Yang, A. and He, W. (2011) Quality of Life and near Vision Impairment Due to Functional Presbyopia among Rural Chinese Adults. Investigative Ophthalmology \& Visual Science, 52, 41184123. http://dx.doi.org/10.1167/iovs.10-6353

[85] Broman, A.T., Munoz, B., Rodriguez, J, Sanchez, R., Quigley, H.A., Klein, R., et al. (2002) The Impact of Visual Impairment and Eye Disease on Vision-Related Quality of Life in a Mexican-American Population: Proyecto VER. Investigative Ophthalmology \& Visual Science, 43, 3393-3398.

[86] Patel, I., Munoz, B., Burke, A.G., Kayongoya, A., McHiwa, W., Schwarzwalder, A.W., et al. (2006) Impact of Presbyopia on Quality of Life in a Rural African Setting. Ophthalmology, 113, 728-734. http://dx.doi.org/10.1016/j.ophtha.2006.01.028

[87] Luo, B.P., Brown, G.C., Luo, S.C. and Brown, M.M. (2008) The Quality of Life Associated with Presbyopia. American Journal of Ophthalmology, 145, 618-622. http://dx.doi.org/10.1016/j.ajo.2007.12.011

[88] Awdeh, R.M., Elsing, S.H., Deramo, V.A., Stinnett, S., Lee, P.P. and Fekrat, S. (2010) Vision-Related Quality of Life in Persons with Unilateral Branch Retinal Vein Occlusion Using the 25-Item National Eye Institute Visual Function Questionnaire. British Journal of Ophthalmology, 94, 319-323. http://dx.doi.org/10.1136/bjo.2007.135913

[89] Chia, E.M., Mitchell, P., Rochtchina, E., Foran, S. and Wang, J.J. (2003) Unilateral Visual Impairment and Health Related Quality of Life: The Blue Mountains Eye Study. British Journal of Ophthalmology, 87, 392-395.

[90] Brown, M.M., Brown, G.C., Sharma, S., Busbee, B. and Brown, H. (2001) Quality of Life Associated with Unilateral and Bilateral Good Vision. Ophthalmology, 108, 643-647 (Discussion 47-48). http://dx.doi.org/10.1016/S0161-6420(00)00635-7

[91] Lin, J.C. and Yang, M.C. (2010) Correlation of Visual Function with Health-Related Quality of Life in Glaucoma Patients. Journal of Evaluation in Clinical Practice, 16, 134-140. http://dx.doi.org/10.1111/j.1365-2753.2009.01135.x

[92] Seland, J.H., Vingerling, J.R., Augood, C.A., Bentham, G., Chakravarthy, U., deJong, P.T., et al. (2011) Visual Impairment and Quality of Life in the Older European Population, the EUREYE Study. Acta Ophthalmologica, 89, 608613. http://dx.doi.org/10.1111/j.1755-3768.2009.01794.x

[93] Vu, H.T., Keeffe, J.E., McCarty, C.A. and Taylor, H.R. (2005) Impact of Unilateral and Bilateral Vision Loss on Quality of Life. British Journal of Ophthalmology, 89, 360-363. http://dx.doi.org/10.1136/bjo.2004.047498

[94] Pokharel, G.P., Selvaraj, S. and Ellwein, L.B. (1998) Visual Functioning and Quality of Life Outcomes among Cataract Operated and Unoperated Blind Populations in Nepal. British Journal of Ophthalmology, 82, 606-610. http://dx.doi.org/10.1136/bjo.82.6.606

[95] Tran, H.M., Mahdi, A.M., Sivasubramaniam, S., Gudlavalleti, M.V., Gilbert, C.E., Shah, S.P., et al. (2011) Quality of Life and Visual Function in Nigeria: Findings from the National Survey of Blindness and Visual Impairment. British Journal of Ophthalmology, 95, 1646-1651. http://dx.doi.org/10.1136/bjo.2011.204693

[96] Cahill, M.T., Banks, A.D., Stinnett, S.S. and Toth, C.A. (2005) Vision-Related Quality of Life in Patients with Bilateral Severe Age-Related Macular Degeneration. Ophthalmology, 112, 152-158. http://dx.doi.org/10.1016/j.ophtha.2004.06.036

[97] Chia, E.M., Wang, J.J., Rochtchina, E., Smith, W., Cumming, R.R. and Mitchell, P. (2004) Impact of Bilateral Visual Impairment on Health-Related Quality of Life: The Blue Mountains Eye Study. Investigative Ophthalmology \& Visual Science, 45, 71-76. http://dx.doi.org/10.1167/iovs.03-0661

[98] Finger, R.P., Fenwick, E., Marella, M., Dirani, M., Holz, F.G., Chiang, P.P., et al. (2011) The Impact of Vision Impairment on Vision-Specific Quality of Life in Germany. Investigative Ophthalmology \& Visual Science, 52, 36133619. http://dx.doi.org/10.1167/iovs.10-7127

[99] Mills, R.P., Janz, N.K., Wren, P.A. and Guire, K.E. (2001) Correlation of Visual Field with Quality-of-Life Measures at Diagnosis in the Collaborative Initial Glaucoma Treatment Study (CIGTS). Journal of Glaucoma, 10, 192-198. http://dx.doi.org/10.1097/00061198-200106000-00008

[100] Janz, N.K., Wren, P.A., Lichter, P.R., Musch, D.C., Gillespie, B.W. and Guire, K.E. (2001) Quality of Life in Newly Diagnosed Glaucoma Patients: The Collaborative Initial Glaucoma Treatment Study. Ophthalmology, 108, 887-97 (Discussion 98).

[101] Brenner, M.H., Curbow, B., Javitt, J.C., Legro, M.W. and Sommer, A. (1993) Vision Change and Quality of Life in the Elderly. Response to Cataract Surgery and Treatment of Other Chronic Ocular Conditions. Archives of Ophthalmology, 111, 680-685. http://dx.doi.org/10.1001/archopht.1993.01090050114040

[102] National Eye Institute (2010) Eye Health Needs of Older Adults Literature Review. http://www.nei.nih.gov/nehep/research/The_Eye_Health_needs_of_Older_Adults_Literature_Review.pdf 
[103] Vela, C., Samson, E., Zunzunegui, M.V., Haddad, S., Aubin, M.J. and Freeman, E.E. (2012) Eye Care Utilization by Older Adults in Low, Middle, and High Income Countries. BMC Ophthalmology, 12, 5. http://dx.doi.org/10.1186/1471-2415-12-5

[104] Stuen, C. and Offner, R. (1999) A Key to Aging in Place: Vision Rehabilitation for Older Adults. Physical and Occupational Therapy in Geriatrics, 16, 59-77.

[105] Luo, R.J., Liu, S.R., Tian, Z., Zhu, W.H., Zhuo, Y.H. and Liao, R.D. (2011) Rehabilitation of Vision Disorder and Improved Quality of Life in Patients with Primary Open Angle Glaucoma. Chinese Medical Journal (Engl), 124, 26872691.

[106] Jackson, M.L., Wallis, J., Schoessow, K., Drohan, B. and Williams, K. (2012) Visual Function in the “Oldest-Old” 1 Year after Comprehensive Vision Rehabilitation. Journal of American Geriatrics Society, 60, 183-185. http://dx.doi.org/10.1111/j.1532-5415.2011.03742.x

[107] Cole, B.L. (2011) Low-Vision Care: We Are Doing Better but Not Well Enough. Clinical and Experimental Optometry, 94, 119-120. http://dx.doi.org/10.1111/j.1444-0938.2011.00593.x

[108] Brown, G.C. (1999) Vision and Quality-of-Life. Transactions of the American Ophthalmological Society, 97, $473-511$.

[109] Frost, A., Eachus, J., Sparrow, J., et al. (2001) Vision-Related Quality of Life Impairment in an Elderly UK Population: Associations with Age, Sex, Social Class and Material Deprivation. Eye (Lond), 15, 739-744. http://dx.doi.org/10.1038/eye.2001.241

[110] He, M., Xu, J., Wu, K. and Li, S. (1999) A Study on Visual Function and Quality of Life in Elderly Population. Chinese Journal of Ophthalmology, 35, 355-358.

[111] Good, G.A. (2008) Life Satisfaction and Quality of Life of Older New Zealanders with and without Impaired Vision: A Descriptive, Comparative Study. European Journal of Ageing, 5, 223-231. http://dx.doi.org/10.1007/s10433-008-0087-3

[112] Esteban, J.J., Martinez, M.S., Navalon, P.G., Serrano, O.P., Patiño, J.R., Purón, M.E., et al. (2008) Visual Impairment and Quality of Life: Gender Differences in the Elderly in Cuenca, Spain. Quality of Life Research, 17, 37-45. http://dx.doi.org/10.1007/s11136-007-9280-7

[113] Hollands, H., Brox, A.C., Chang, A., Adilman, S., Chakraborti, B., Kliever, G., et al. (2009) Correctable Visual Impairment and Its Impact on Quality of Life in a Marginalized Canadian Neighbourhood. Canada Journal of Ophthalmology, 44, 42-48. http://dx.doi.org/10.3129/i08-167

[114] La Grow, S., Alpass, F., Stephens, C. and Towers, A. (2011) Factors Affecting Perceived Quality of Life of Older Persons with Self-Reported Visual Disability. Quality of Life Research, 20, 407-413. http://dx.doi.org/10.1007/s11136-010-9758-6

[115] Renaud, J., Levasseur, M., Gresset, J., Overbury, O., Wanet-Defalque, M.C., Dubois, M.F., et al. (2010) Health-Related and Subjective Quality of Life of Older Adults with Visual Impairment. Disability and Rehabilitation, 32, 899-907. http://dx.doi.org/10.3109/09638280903349545

[116] van Nispen, R.M., de Boer, M.R., Hoeijmakers, J.G., Ringens, P.J. and van Rens, G.H. (2009) Co-Morbidity and Visual Acuity Are Risk Factors for Health-Related Quality of Life Decline: Five-Month Follow-Up EQ-5D Data of Visually Impaired Older Patients. Health and Quality of Life Outcomes, 7, 18. http://dx.doi.org/10.1186/1477-7525-7-18

[117] Davidov, E., Breitscheidel, L., Clouth, J., Reips, M. and Happich, M. (2009) Diabetic Retinopathy and Health-Related Quality of Life. Graefe's Archive for Clinical and Experimental Ophthalmology, 247, 267-272. http://dx.doi.org/10.1007/s00417-008-0960-y

[118] Brown, G.C. (1999) Vision and Quality-of-Life. Transactions of the American Ophthalmological Society, 97, $473-511$.

[119] Elliott, A.F., McGwin Jr., G. and Owsley, C. (2009) Health-Related Quality of Life and Visual and Cognitive Impairment among Nursing-Home Residents. British Journal of Ophthalmology, 93, 240-243. http://dx.doi.org/10.1136/bjo.2008.142356

[120] McIlvane, J.M. and Reinhardt, J.P. (2001) Interactive Effect of Support from Family and Friends in Visually Impaired Elders. The Journals of Gerontology. Series B, Psychological Sciences and Social Sciences, 56, 374-382. http://dx.doi.org/10.1093/geronb/56.6.P374

[121] Reinhardt, J.P. (1996) The Importance of Friendship and Family Support in Adaptation to Chronic Vision Impairment. The Journals of Gerontology. Series B, Psychological Sciences and Social Sciences, 51, 268-278. http://dx.doi.org/10.1093/geronb/51B.5.P268

[122] Bookwala, J. (2011) Marital Quality as a Moderator of the Effects of Poor Vision on Quality of Life among Older Adults. The Journals of Gerontology. Series B, Psychological Sciences and Social Sciences, 66, 605-616. http://dx.doi.org/10.1093/geronb/gbr091

[123] Watson, G.R. (2001) Low Vision in the Geriatric Population: Rehabilitation and Management. Journal of American 
Geriatrics Society, 49, 317-330. http://dx.doi.org/10.1046/j.1532-5415.2001.4930317.x

[124] Cox, A., Blaikie, A., Macewen, C.J., Jones, D., Thompson, K., Holding, D., et al. (2005) Optometric and Ophthalmic Contact in Elderly Hip Fracture Patients with Visual Impairment. Ophthalmic and Physiological Optics, 25, 357-362. http://dx.doi.org/10.1111/j.1475-1313.2005.00307.X

[125] Tsai, S.Y., Chi, L.Y., Cheng, C.Y., Hsu, W.M., Liu, J.H. and Chou, P. (2004) The Impact of Visual Impairment and Use of Eye Services on Health-Related Quality of Life among the Elderly in Taiwan: The Shihpai Eye Study. Quality of Life Research, 13, 1415-1424. http://dx.doi.org/10.1023/B:QURE.0000040791.87602.fe

[126] Wang, C.W. and Chan, C.L. (2009) Psychosocial Adaptation Status and Health-Related Quality of Life among Older Chinese Adults with Visual Disorders. Quality of Life Research, 18, 841-851. http://dx.doi.org/10.1007/s11136-009-9505-Z

[127] Zhang, X.J., Wang, A.P. and Yin, A.C. (2014) The Impact of Psychosocial Adaptation Status on Quality of Life for Chinese Patients with Visual Impairments. Journal of Clinical Nursing, 23, 75-81. http://dx.doi.org/10.1111/jocn.12041

[128] Wang, C.W., Chan, C.L., Ng, S.M. and Ho, A.H. (2008) The Impact of Spirituality on Health-Related Quality of Life among Chinese Older Adults with Vision Impairment. Aging and Mental Health, 12, 267-275. http://dx.doi.org/10.1080/13607860801951903

[129] Voytas, J.J. (2005) Unmet Visual Needs in the Nursing Home: Wait until Dark? Journal of American Medical Directors Association, 6, 284-285. http://dx.doi.org/10.1016/j.jamda.2005.05.007

[130] Wedding, U., Pientka, L. and Hoffken, K. (2007) Quality-of-Life in Elderly Patients with Cancer: A Short Review. European Journal of Cancer, 43, 2203-2210. http://dx.doi.org/10.1016/j.ejca.2007.06.001

[131] Brody, B.L., Roch-Levecq, A.C., Gamst, A.C., Maclean, K., Kaplan, R.M. and Brown, S.I. (2002) Self-Management of Age-Related Macular Degeneration and Quality of Life: A Randomized Controlled Trial. Archives of Ophthalmology, 120, 1477-1483. http://dx.doi.org/10.1001/archopht.120.11.1477

[132] Campbell, A.J., Robertson, M.C., La Grow, S.J., et al. (2005) Randomised Controlled Trial of Prevention of Falls in People Aged > or $=75$ with Severe Visual Impairment: The VIP Trial. BMJ, 331, 817. http://dx.doi.org/10.1136/bmj.38601.447731.55

[133] Eklund, K., Sonn, U. and Dahlin-Ivanoff, S. (2004) Long-Term Evaluation of a Health Education Programme for Elderly Persons with Visual Impairment. A Randomized Study. Disability and Rehabilitation, 26, 401-409. http://dx.doi.org/10.1080/09638280410001662950

[134] Chen, E.W., Fu, A.S., Chan, K.M. and Tsang, W.W. (2012) The Effects of Tai Chi on the Balance Control of Elderly Persons with Visual Impairment: A Randomised Clinical Trial. Age and Ageing, 41, 254-259.

http://dx.doi.org/10.1093/ageing/afr146 